\title{
The Role of Nutritionists in Primary Health Care: A Case of Narok County Referral Hospital in Narok County
}

\author{
Stellah M Koini* Zeddy Lemein
}

\begin{abstract}
Introduction: The study identifies the perception of users in devolved in primary Health care (PHC) with regards to the role of nutritionists. This study also aims at acknowledging the importance of the nutritionist's work for their health, and verifies their expectations in relation to it. Methods: Semi-structured individual interviews were applied to users of Primary Health Care, under follow up or otherwise with the unit nutritionist. The interviews were transcribed and submitted to a discursive textual analysis. Results: The nutritionist was correctly associated to food, feeding and nutrition, although the boundaries of their function are subtle, suggesting a weak professional identity. The work developed has always been positively evaluated and recognized as important for the users' health. The expectations related to the practice point to the need of humanized and integral care, including more actions for the collectivity - community and team work - in accordance with present health policies. Conclusions: To meet expectations and advance in the professionalization process it is necessary to listen and fulfill the demands, as well as assess the education process and daily practice, taking into account the new paradigms of primary care and health promotion.
\end{abstract}

Keywords: Nutritionist, Primary Health Care, Perception, Narok County.

DOI: $10.7176 / \mathrm{JHMN} / 68-08$

Publication date: November $30^{\text {th }} 2019$

\section{Introduction}

Primary health care came to the spotlight with the promulgation of the new constitution in Kenya in August 2010. The devolution of the Primary Health Care (PHC) was considered a breakthrough in the field of health in the country. Narok County is one among the many hospitals referred to as level five referral hospital. The study highlights the level of attention on the promotion and protection of health, disease prevention, diagnosis, treatment, rehabilitation and maintenance of health, favoring epidemiological and sanitary surveillance, vector control and health education. The study aims at depicting a PHC user's perspective of the role of the nutritionists in primary care. We emphasize the important role of the nutritionists in the offering of nutrition services, and currently in the hospital; considering that food and nutrition are fundamental human rights, as stated in the Universal Declaration of Human Rights 2015, they are basic requirements for the promotion and protection of health. Countries like Brazil in their declaration in 2010 included the right to food as a social right for the population. According to the Ministry of Health, Kenyan has committed to promoting healthy eating, due to the intricate nutritional situation of the population, which is undergoing a nutrition transition. Rising rates of lifestyle diseases coexist with major prevalence of deficiency, such as vitamin A deficiency and iron deficiency anemia, as well as hunger. Kenyan government is strongly committed to reducing hunger and malnutrition. This includes efforts to built capable staffing to assist those in need when emergencies occur. The Ministry of Health approved and in 2011 renewed the Food and Nutrition Security Policy (FNSP) provides an overarching framework covering multiple dimensions of food security and nutrition improvement. It has been purposefully developed to add value and create synergy to existing sectoral and other initiatives of government and partners. It recognizes the need for multi-public and private sector involvement, and that hunger eradication and nutrition improvement is a shared responsibility of all Kenyans. The policy and associated actions will remain dynamic to address contextual changes and changing conditions over time. This policy is framed in the context of basic human rights, child rights and women's rights, including the universal 'Right to Food'. The policy further, devotes its guidelines to promoting nutritional health, with the dietitian in charge of turning these guidelines into action. This study highlights the role of the nutritionists in primary health care, from the perspective of healthcare providers who are more than service consumers, they are citizens who can gather to get what they want and from different origins and necessities. It is essential to understand their diversity and pursue in them, through diagnostics (individual and collective), objectives and targeted health actions. The healthcare providers play an essential role in the formation and running of the system itself. They constitute half of the representation on the Boards of Health - social control, where the user directly chooses how health should be led in their community and in the remaining spheres. Nutritionists in primary health care studies the perception of users and workers on the devolved Health systems in Kenyan referral hospital. There was a correlation between the proposition of nutritionists to the community and the change in community welfare in terms of health - demonstrated through the users' report and satisfaction. In the final considerations, the importance of such assessment is depicted from the perspective of the agent and the user, considering the collective construction of healthcare providers. The study further addressed the view of users on access and cares in Narok the county referral hospital identifying drivers of facilities and difficulties that affect the quality of care. The study 
brings out the importance of the aspects studied for the qualification of the health service by users, through their starring role in the health system, causing direct impact on improving the relationship between users and service. They show that the identification of competent and reliable staff in the team, considering experience and ability, are factors that greatly influence choice in health service. A study in Narok referral hospital demonstrates that prevention and health promotion actions and the professional-user relationship were positively assessed, while access to health services, medication and professionals were negatively evaluated. The actions taken by the county health unit failed to ensure the principles of comprehensiveness, and it was necessary to revise strategies, especially those that increase community participation. In the user nutritionist relationship, we may highlight various aspects related to user perception, which are directly linked to issues of professionalization. Another study exposed the need for society to acknowledge the distinctive knowledge included in the training of the staff. The user in this study can be considered representative of this society, and, therefore, it is from their view that one should evaluate the acknowledgement of the fundamental aspects of the qualification of nutritionist thus this proves the relevance of understanding user perspective on the role of the nutritionists regarding their health.

\section{Methods}

This is an exploratory and qualitative study, characterized as able to incorporate the question of meaning and intentionality to actions relationships and social structures, understanding social reality of food, nutrition and health. The sample consisted of primary care workers in Narok county referral hospital. These are from health units that include nutritionists who agreed to participate on the research. The research subjects were direct users of nutritional services and indirect users. The purpose of addressing these two groups was to include a more comprehensive view of the nutritionist, avoiding a possible bias on the data provided only by users with direct contact with that professional. The sample was determined through shortage criteria recurrent thoughts presented by the respondents. For data collection, short-term interviews were used with semi-structured questionnaire. The aspects addressed in the research script were: awareness of the activities performed by nutritionists, the importance or relevance to their health and that of the community, and expectations in relation to the work of that professional. The interviews were recorded and written down, and the content was transcribed. Data were used with the permission of respondents through a Statement of Informed Consent, according to the Ethics Committee in Research of Kenyatta University, which approved the project under Decree Ref: KU/R/COMM/51/625. This is an essential condition to the use of data, respecting the confidentiality of individuals. After transcribing the interviews, they were transformed into texts in which discursive textual analysis was used. Investigation of all the information allowed for the emergence of analytic categories, result of the dialogue between the theoretical model and the data. For each category, in the undergoing of cyclical readings and analysis, a text was produced, seeking to express the set of existing meanings. Further, a comprehensive analysis was conducted: the articulation of descriptive analysis with view on the theoretical framework and with understanding arising from these, resulting in the final text.

\section{Results and discussion}

Out of the 34 nutritionist currently the referral hospital has 7 nutritionist, meaning there is under staffing in that area. Prevailing females, aged between 18 and 60 years were interviewed. The study showed high women response rate of $86.1 \%$ this is justified by the fact that they seek health services more often. In the study $23.1 \%$ of the respondents stated that they were not being assisted by a primary care nutritionist. The other $38 \%$ expressed that they were being monitored for at least three months and had had their first appointment recently. Some themes that were presented were defined according to data collected. The nutritionist and their interfaces from the perspective of the respondent's category appears that nutritionist and how they are perceived by the respondents is who he is? How he is and the activities performed. In seeking to identify how the respondents perceives the role of the nutritionist, there is agreement with the findings of Pauline Müller Pacheco and Maurem Ramos; this authors reported that the nutritionist: comes within the health sector, with the objective to work towards man feeding in their individual and collective levels. Respondents, were unanimous as to the nature of the work of nutritionist be related to food and nutrition. In reality it's evident from the statements of the interviewees: who stated that nutritionists guide us to eat a little better; to have a good diet; one respondent said that nutritionist takes care of your health and take care of the person. As noted from respondents, that apart from treating nutrition deficiencies food is also recognized as an influence on the health of users. Another respondent stated that, "She wanted help on how to maintain her health." Health promotion is one of the general principles of basic care. Likewise, public health nutritionist emphasizes that "feeding and nutrition are basic requirements for the promotion and protection of health, enabling the full expression of growth potential and human development, quality of life and citizenship". Thus, professional nutritionists these units are perceived as health promoters, health policies advocated by force. Among the activities and skills that users report being Nutritionist, is the idea of teaching. In interviews, appears in the form of "food reeducation" or "get the science." However, it seems unclear whether this is just a reproduction of the discourse of a nutritionist or actually reflects the users' perception of one learning new eating behaviors, since the approach was always using a food plan without reporting the use of other educational methodologies. 
One respondent affirmed that the nutritionist offered a diet "for re-educating and eating habits, a diet to make me learn how to eat well". Another respondent said that: "a nutritionist gave guidance about diet, education on the right eating habits." The concept of "food education" is closely linked to the history of actions and political power in Kenya, undergoing many changes over time. It started from time in memorial, based on the "myth of ignorance" the low-income population in relation to their food, which would be the major determinant of malnutrition. New perspectives consolidated food and critical nutritional education based ". The principles of critical pedagogy content, Marxist-oriented, considering that nutrition education is not neutral, but also can not follow a fixed methodology." food, nutrition \& health Currently, with the term public health nutrition, presents food and nutrition education as a process of dialogue between health professionals and the public, focused on autonomy and selfcare, referencing the site and considering the reality that social inequalities interfere in human right to adequate food. According to the above, the food and nutrition education has consolidated concept, as it should be a collective construction, with the goal of changing behavior in an integrated reality of the person, family or community process. While education and food and dietary education emerged as the dominant discourse, the term "diet" was also present. In 1986, Gill8 pointed out that: "the dietitian is not just a technical calculator and planner diets menus". Thus, it should not be seen within this simplistic perspective, since, according to the same author, professional degree in Nutrition Search the phenomena in their entirety, having significant role and usefulness of our country. When the definition of what is the job of a nutritionist or reference the same theme in other moments of the interview, the professional was mistakenly called by the name of other professions. One respondent said that: "a nutritionist is virtually a doctor." Apparently, the role of the nutritionist is correctly associated with their field of knowledge and working tools; however, the limits of its performance seem tenuous, not setting a wellestablished for the user identity. The result is consistent with the assertion of Banduk, Ruiz-Moreno and Batista: The existence of the profession of nutritionist in Kenya, for more years, still does not guarantee a professional identity clearly perceived by Kenyan society. The confusion between the professions of physician and nutritionists is possibly due to the fact the medical term being used to refer to what is known as a health professional. Being the identity of unclear nutritionist, confusions arise. Bosi puts it, between semi-professions; Nutrition is among those that will not become a profession. As the author acknowledges that the process of professionalization is dynamic, one can observe an aspiring dietitian in the shadow of a dominant profession, which has a monopoly of a group of knowledge already recognized by society, which legitimize the domain carrying occupation. The nutritionist was also quoted as justifying conduct of professionals in psychology and physical education activities. Thus, another respondent mentioned that:" Nutritionists in primary health care established that psychology seems to be because the relationship between man and the food beyond the biological issues, and treatment involves listening to the problems and openness to social and emotional issues, which implies a more comprehensive care beyond the physical symptoms. As noted in the respondent, respectively: "She takes care of everything she cares what you do well, eg, what makes you good for your health." And: "She wants to help, wants to maintain their health." For the document from the Ministry of Health that addresses the comprehensive care of NCDs, care is part of life and live the human being, and according to Valla and Lacerda, it refers to an act of respect and accountability, constituting an 'interactive approach that includes the involvement and the relationship between the parties, including host, listening subject'. The association with activities of professionals in physical education may be linked to the guidelines for physical activity by the dietitian, as a recommendation for a healthy life. This guidance is consistent with the recommendations in the publication Ten Steps to Healthy Eating, which poses as the ten step regular physical activity. This aspect of the agenda issues of delimitation of the powers of the areas of expertise and knowledge of each profession, as well as the limitations of the composition of health teams. In case, the dietitian may recommend physical activity, but cannot establish the terms in which it should be performed, since it is incumbent on the Physical Education Professional. Importantly, psychologists and physical educators not made up the staff of the surveyed units, although apparently there is a demand for them. Thus, all the unit staff, and not just the nutritionist receive these demands and the response we give them (something that cannot be adequately assessed in this study) may be part of the perceived confusion found in the speeches. This study also sought to identify characteristics that users attribute their performance nutritionist. For all respondents, the nutritionist was always qualified positively. One respondent confirmed: "I think so, her work is excellent." And another respondent: "But I like the person, the way she treats her patients." Specific skills were highlighted as understanding test results or perform physical assessment and screening. Also the link that appears in various forms such as empathy, humane care, concern, care and even the requirement. Empathy emerged as affinity, highlighted by another respondent: "And all that well, I think people just have more in common, I guess so well she hit me." The human feeling is present in professional conduct, according to "She's very human knows, she understands the human being." A relationship is established with the policy of humanization, which has among the guiding principles valuing subjective and social dimension in all care practices and gestão. It should be noted that these statements do not mean that all bond the principles of political are serviced. Food, nutrition $\&$ health The appreciation of the subjective dimension of care is referred to as user-bonding capability of the professional and demonstrating sincere interest in their demands. Another respondent said: "she is very interested, too 
demanding, it is imposed." Such aggregating aspects of the professional user relationship, from which there is greater openness to contact, listening, understanding and problem solving at diagnosis and during the nutritional treatment are highlighted by the research subjects. Just as confirmed by another respondent: When she approaches, she hugs us, she kisses us, she talks, she treats you as if you were a friend from long ago. That gives you the freedom to act and talk with her and tell what you are openly feeling. They also denote her attention, understanding of the problems exposed, the explanation offered in the guidelines and their understanding as professional responds to the demands of users. Another respondent commented: "She gives you attention, she explains you why, how, what's right, what is wrong, how to correct power." Another responded said that: "I received a lot of attention from the nutritionists who was worried much with us, did not rush, so it's very important." The nutritionist is also valued by the very fact of acting in solving food problems. It is possible that the phenomenon is caused by the satisfaction of an emerging demand in food and nutrition. Guiding questions relating to the activities developed by nutritionists, some users have reported indirect unaware of any activity: "I do not know what job he develops because until then I could not even get in, consult with a nutritionist, nor do I know what they do" said another respondent. Among the activities mentioned by the other respondents are the individual sessions, support of families in Narok. Regarding the procedures adopted in individual consultations, there was reported guidelines for food, increased water consumption, reducing power; a medical interview, conducting food recall, examinations, measurement of anthropometric data, physical activity orientation with supervision of other professionals or not, use of tables unspecified, as well as its use, guidance on foods high in calories, guidance on feeding infants. Modalities of care cited refer to the individual or to the actions of policy implementation clinical care. There is, however, evidence that these users do not realize the activities accomplished by professionals in the community, even if these are carried out effectively. Another respondent stated: Look, I know that nursing has it, and if she has suddenly gotten there too, she always has, let's say a patient comes out, and then another enters, they will have enough attention. Nutritionists in primary health care are the community is a subject of action for Matrix Actions on Food and Nutrition in Primary Care whose main purpose is: "systematize and organize the actions of food and nutrition and nutritional care to join the roster of health actions undertaken in primary care. "So it is important to think about the actions developed by nutritionists in this study tool. Shares in the Matrix, when the question arises of the role of the nutritionist in primary care, this is said, about their responsibilities: They have as main objective to contribute to the planning and organization of activities for local nutritional care, aiming to classify the services and improving their solvability, acting effectively on the determinants of health problems and food and nutrition problems affecting the population of that territory. The document continues with the importance of strengthening actions from nutritionists to improve the quality of life of the population, health promotion, promotion of food security and nutrition, involving three subjects of shares: the individual, the family and the community. Added to this the training of professional service and the articulation of strategies with social equipment of its territory. The work, being limited to individual and restricted to the physical space of the health unit actions, or in other areas where it is prevalent, it is the only perceived by users, will also have their results limited to this sphere. This partially working, the legacy of a biology and individualistic health model - can result in low effectiveness problems connected to the public health nutrition. The development of a multidisciplinary approach "may contribute to the effectiveness of the actions of nutrition, from the shared construction of knowledge". However, this work cannot be based only on formal articulation, bureaucratic - in reality of health services can be translated by reference and counter mechanisms. Connections team should already start training, and professionals should engage effectively with the work they intend to execute. This is an agreement with some of the challenges of practicing social nutritionist overcoming the training model, generating practices conventional and fragmented, which are reflected in a work team also fragmented. Food, nutrition $\&$ health thus, one can understand that the ways of professional performance are closely linked to the paradigm that underpins their training, which nowadays has been questioned, with the need to seek a downsizing in different aspects: knowledge and training and practice. Importance of the nutritionist in primary care, The matrix of shares of food and nutrition in primary health care presents the idea of the importance of the issue in professional practice: Kenyan's current epidemiological situation represented by the double burden of disease is reason justifying the merger of shares of food and nutrition in the context of primary health care in general and, in particular, of the Family Health Strategy. In the context discussed in this study, the nutritionist was crucial, according to all respondents, although some are unable to explain their reasons. Another respondent argued: "I think it's important to have a nutritionist. It does matter to have a nutritionist at the post. "And yet, the fact of not performing service with the nutritionist did not represent a disincentive for the user to issue his opinion on the importance of work in the unit. One reason was that the dietitian offers support, guidance gives specific and differentiated. Said they had received no information obtained by other means, and when asked about what they thought about the health unit no longer count with a nutritionist, reports were unanimous in pointing out that it would be a great loss to the community. One respondent thus commented that: "she learned from nutritionist' things she has not learned from anywhere else." And another respondent added, "Before then I would never have that guidance and would have gone back to bad eating habits. Nutritionist knows everything that you will not have known, if you don't visit the hospital or ask for guidance. Respondents denote 
that users perceive that the activities and skills of nutritionists cannot be met by other health professionals of the unit. Even facing the confusion of professional boundaries previously reported, it appears that the field of knowledge of nutrition and its tools work overlap, suggesting that users consider the activities of transferable nutritionist. This relates to the specificity of knowledge. Nutritionists in primary health care as per Demetra; 2014; 9(2); 483-501 493 The sociology of professions, according to Bosi, believes that the knowledge and skills specific profession must convince society that the members of this profession: "are possessors of knowledge that characterizes differentiated from those who did not follow the same training ", which makes the knowledge base of the profession in favor of professionalization. Thus, although, as already noted above, there is a weak professional identity Nutritionist, one can observe that the results of this study present evidence favorable to the professionalization process. The importance of the presence of a nutritionist was quoted, in view of the people who were already in treatment, or that they might express demand for the professional. These individuals would lose support and then would find the downside to not rely more on professional nutritionist in the unit. Realized on the testimony of the respondents: "She will be missed so, people will miss her." In this regard, it was reported that some do not feel the difference, not because the treatment had not been relevant, but because the basis of change in feeding behavior and knowledge for it had already been made. This result may reflect the extent of user autonomy in relation to their treatment. Moreover, the importance of professional nutritionist was highlighted due to health problems or specific diseases in the community that justify the presence of a nutritionist in the unit. Another respondent argued that: "It is important for the community, you know, because it has many obese people." This can be translated in the same way as was discussed earlier, as the population feels it would lack support for solving problems related to diseases and disorders linked to issues relating to food - this is a specific skill and expertise of the nutritionist. The importance of the presence of nutrition professionals in primary health care seems to be recognized by society, according to the findings in this research. This is one more argument for the gradual integration of nutritional care in primary care is already provided in Matrix Actions on Food and Nutrition in Primary Care. In that same document, it is still argued that: The role of the nutritionists in most municipalities needs to be strengthened so that the capability and knowledge of nutrition interventions in this field may, effectively, contribute to improving the quality of life and health of the population. It can be noticed that the emerging situation is charting a path where the real need for qualified professionals to work with the issue of power in basic carefully, humanized and interdisciplinary agree with the policies of current health, noting the inclusion of professional and compliance of proposed actions on these policies. Food, nutrition \& health is the expectations of nutritionists' social practice expectations regarding the role of the nutritionist mentioned by respondents were related to the activities to be undertaken and forms of conduct in nutritional care. In relation to conduct in nutritional care, patience and acceptance of anxieties were considered crucial in the professional-user. Patience apparently not meant indulgence of relapse in treatment. Several reviewers have stated the importance of the collection, the "rigor" that can translate the importance of Africa in support of the valuation results achieved by the patient that the nutritionist is "investing". Other aspects such as commitment and consistency were addressed. Another respondent that argued: "You have to take very seriously, do not get simply going on a diet"; and another respondent, "is whether to treat these poor people for it was difficult for them to speak what the person will understand, not to mention more difficult terms, so to speak as if they were equal to those people." The importance of evaluating the costs of food and the availability of finance for the development of coherent guidelines for the treatment was raised by several users. The study had to first analyze the financial condition, the diet, according their financial situation and also according to my body. Another respondent stated that Technical competence was addressed in different ways. On the one hand, the technical knowledge was recognized as necessary for the nutritionist to act as an agent of transformation through education, another said that. "She's using all science, all she studied to pass them right, so I can help," Also, the technician can do represent a negative to establish a good relationship between the user and the professional factor, as a respondent noted, "if she wanted to learn to speak up, or did not want to accept, I already saw that she was not a person who had so much interest in people, treatment, right. She wanted to go through her study, huh, guess she did not want to accept from others. "Supposedly, that technical competence is recognized as essential and is one of the expected characteristics of a good professional this without interfering with the listening space or interferes with the user participation in the primary care service in choosing your own treatment, compromising thus its autonomy. Another issue raised was the amount attributed to motivation. This was stated by one respondent said that; Nutrition is stimulating person to person and always go back and do the nutrition another said that it is a pleasant thing, a thing that makes you want to come when" The rise in self-esteem is another way in which the question of motivation arises in the statements. The stimulus factors were not listed, but you can understand that all aspects covered above as the expected behavior of the dietitian are motivators of adherence to treatment, by creating and strengthening the bond-professional user. We deduce that the users' perception of the action Nutritionist is restricted to individual care, which may reflect the way health services are organized. The group approach in the perspective of the public health interest facilitate the learning process and ownership of other forms of health care, as argued by one respondent: The group activity will help: "need to walk, will walk alone," these things, then brings people together and at least at a certain time 
practicing an activity. With everyone together, meeting then goes all together, everybody together, with that goal. The group activity in hospital and community was raised as an alternative to actions within the health unit, both in the case of the educational aspect or information, as of social activities. I think the hospital, should help people who are slightly overweight, by advising. Such a person is not always expected to look for advice from nutritionists. They could have a meeting with all the people whom they share these problems and always seek advice from them. The subject "group" not only emerged as a theme related to public health nutritionists, since the idea emerged nutritionist involve health staff, its own working group activities on food and nutrition. Another respondent supports this thought: "the power of peers, guide them how to eat better, how to make a healthy food." The value of working with the team is justified in several ways. First, the need for ongoing education of staff for issues of nutrition. Second, by providing tools for quality of life, and therefore improve the health of the worker. Finally, the possibility of having a space where staff can share experiences, create together and reaffirm their own bonds. Food, nutrition \& health activities in the community outside the physical area of the health unit, these are also considered strange to respondents. None of the users, whether direct or indirect, known quote some activity with the criteria developed by the nutritionist. Some cite this type of activity as "voluntary" or that concerned "personal life" Nutritionist, and thus demonstrate not realize as part of professional practice in primary care development activities with the community. At the same time, comprehensive report that more work demand as claimed by another respondent that: They should, be more nutritionist in the community and homes to see the situation, there are people who barely feeds the children in needy community, go there to see what the situation is, how it is feeding these children, not only worry about the obese. Lack of guidance from families, mothers, parents on how to feed their children properly. Other users have also indicated the importance of working with children, citing the school as a place for conducting activities. Spending on schools to adequate food by giving dietary guidance for children. The respondent further stated that; the work with children can be extended to parents: "I think one thing was that nutritionists could visit schools, give guidance for pupils, students suddenly lead to parents." Another area cited were the homes of aged care, their difficulty of access to the facility. The same way that the elderly cannot reach the unit, respondents claim that the community did not demand the health service, lack of interest or because they are unaware of the work of nutrition. So, work out at the health facility would facilitate the approach, enabling greater coverage and preventive actions. The study expressed this thought that something could be done for those in the community who are economically unstable because of difficulties. Lowincome people even are an area that is not very popular for them to seek general practitioner help and who seek nutritionist help. The type of activity suggested ranged from educational activities, as expressed by a respondent, that could give guidance to people who the nutrition needs care. They expressed the need of self push towards the people, rather than making them come to the office because they will not come, the care should be through associations that could target low income communities. Nutritionists in primary health care within the proposed educational activities also proposed to be teaching on kitchen activities and how cook their own food understood. Nutritionist were suggested have some lessons for the community, they thought it would be well accepted by the people, in the community. Recreational and social activities were brought, and were expressed in this statement as: "have a picnic there for us to spend time there talking, having fun and telling something and Take a walk along ". It is worth recalling here that the community - one of the three subjects of the Matrix Ações23 approach - should be seen as more than a sum of individuals, as a collective subject, whose actions performed allow "keeping with the look and of care required by the construction of a new model of health care "strategy, which is based on primary health care. These actions have the potential to give greater attention to solving the health promoting integrative and, more than that, it coordinates the actions of health surveillance will impact the epidemiological profile of the population. It was expressed that the nutritionist could collaborate with major problems of the community as a spokesperson to the organs of government. That they would have to enter the hall and help, because none could do it alone, money could not be the problem but, community representation was very key. "This may be the symptom of a lack of community leadership, poor participation in social control or even the lack of structure of the Board of Health, which makes the user look professional with which one identifies a spokesman for his demands. This perspective goes against the issue of client autonomy for health decisions. Buss and Ferreira state that health promotion has been expanding from established at the First Conference, with new elements such as "promotion of social responsibility with the empowerment of the people." As a professional primary health care, the dietitian is the premise of seeking to promote health, besides encouraging healthy eating, working according to its other principles, including stimulating role through health education. According to Buss empowerment of the population organized as central to the promotion of health claims for healthy public policy strategy, as follows: "an indispensable condition for the viability and effectiveness of public policy." Food, nutrition \& health also state the role of health education as touted towards development of knowledge, but as a driver of behavior and attitudes, including the encouragement of community participation in health decisions. Importantly, health education for these purposes depends on overcoming conventional and fragmented practices, as pointed out by Ferreira and Magalhães, as realization to necessite the collective, and thus promotes their protagonist. 


\section{Conclusion}

It is necessary to establish that the results of this study are not intended for generalization of its qualitative character and not epidemiological. It provides tools to think from a new point of view the public health care, how they are being perceived practices of dietitians in primary care. The response from the literature review of this study showed the fragility of possession of stored data, to date, on the user perception of the public health in general and specifically in Porto Alegre-RS, regarding the role of the nutritionist in primary care. Responses applied, however, research showed that there Nutritionist recognition in primary care as a professional in the area of food and nutrition, exerting positive influence on the health of participants in the study. Even if the nutritionist is recognized within the core of their powers, the limits of its performance seem tenuous, demonstrating an unclear identity. Thus, it is necessary to know and think about how to develop the process of professionalization, considering the need for changes in education and practice, placing them in favor of professional recognition category. The findings demonstrate the work of very targeted to dietician in individual stocks and restricted to the health unit level physical limits, mode of action that appears to be closely linked to a too fragmented and biological training, which in turn hinders the action plan team. This is another of the challenges of professional practice: teamwork, present at bases and training that reflects more integrative practices in the community and the family, strengthening collective and class actions for the promotion of health and the development of community leadership. The nutritionist has always been highly regarded positively - possibly due to issues related to the bond in its various aspects - and was crucial, according to all respondents - what a justification for offering support and guidance specific and differentiated. This last feature is also favorable to the professionalization process and according to the guidelines of the Department of Primary Health Care, Ministry of Health. Nutritionists in primary health care expectations expressed by the research subjects formed a framework of precious information about what is important to be offered to the community at that time and how those people expect to be treated. Constitute a set of tools that can assist the dietitian in its fundamental goal of promoting your health reference population and reinforce the importance of a permanent place to listen to the user. In order to obtain a more comprehensive picture about the user's perception of primary care on the dietitian, more studies should be done, considering the scarce literature on the subject of nutritionists, particularly in the field of Public Health under the perspective of the user.

\section{References}

1. Oliveira DC, Sá CP, Gomes AMT, Ramos RS, Pereira NA, Santos WCR. A política pública de saúde brasileira: representação e memória social de profissionais. Cad. Saúde Pública 2008; 24(1):197-206.

2. Ferreira VA, Magalhães R. Nutrição e promoção da saúde: perspectivas atuais. Cad. Saúde Pública 2007; 23(7):1674-1681.

3. Brasil. Emenda Constitucional n ${ }^{\circ}$ 64, de 4 de fevereiro de 2010. Altera o art. $6^{\circ}$ da Constituição Federal, para introduzir a alimentação como direito social. Diário Oficial da União 4 fev. 2010.

4. Brasil. Ministério da Saúde. Política nacional de alimentação e nutrição. Brasília: MS; 2003.

5. Silva GGA, Egydio MVRM, Souza MC. Algumas considerações sobre o controle social no SUS: usuários ou consumidores? Saúde em Debate 1999; 23(53):37-42.

6. Brasil. Ministério da Saúde. Diretrizes e recomendações para o cuidado integral de doenças crônicas nãotransmissíveis: promoção da saúde, vigilância, prevenção e assistência. Brasília: Ministério da Saúde, 2008.

7. Levy FM, Matos PE, Tomita NE. Programa de agentes comunitários de saúde: a percepção de usuários e trabalhadores da saúde. Cad. Saúde Pública 2004; 20(1):197-203.

8. Ramos DD, Lima MAD. Acesso e acolhimento aos usuários em uma unidade de saúde de Porto Alegre, Rio grande do Sul, Brasil. Cad. Saúde Pública 2003; 19(1):27-34.

9. Shimizu HE, Rosales C. Family perspective on a family care program. Rev. Latino-Am. Enfermagem 2008; 16(5):883-8.

10. Bosi MLM. Profissionalização e conhecimento: a nutrição em questão. São Paulo: Hucitec; 1996.

11. Minayo MC. O desafio do conhecimento: pesquisa qualitativa em saúde. 8. ed. São Paulo: Hucitec; 2004. 500 Demetra; 2014; 9(2); 483-501 Demetra: food, nutrition \& health

12. Moraes R. Uma tempestade de luz: a compreensão possibilitada pela análise textual discursiva. Ciênc. Educ 2003; 9(2):191-211.

13. Pinheiro RS, Viacava F, Travassos C, Brito AS. Gênero, morbidade, acesso e utilização de serviços de saúde no Brasil. Ciênc. Saúde Coletiva 2002; 7(4):687-707.

14. Ypiranga L, Gil MF. Formação profissional do nutricionista: por que mudar? Seminário Nacional Sobre Ensino de Nutrição; 1989; Goiânia. p. 19-36.

15. Brasil. Ministério da Saúde. Política nacional de atenção básica. Brasília: Ministério da Saúde; 2006. 16. Lima ES. Gênese e constituição da educação alimentar: uma síntese. Physis: Rev. Saúde Coletiva 1997; 7(2):9-29.

17. Santos LA. Educação alimentar e nutricional no contexto da promoção de práticas alimentares saudáveis. Rev. Nutr. 2005; 18(5): 681-692.

18. Gil M. Recursos humanos em nutrição no Brasil: nutricionistas. Cad. Saúde Pública 1986; 2(4):561-569. 
19. Banduk MLS, Ruiz-Moreno L, Batista NA. A construção da identidade profissional na graduação do nutricionista. Interface 2009; 13(28):111-120.

20. Valla VV, Lacerda, A. As propostas terapêuticas de cuidado integral à saúde como proposta para aliviar o sofrimento. In: Pinheiro R; Mattos RD, organizador. Cuidado: as fronteiras da integralidade. Rio de Janeiro: Hucitec; 2004. p. 91-103.

21. Brasil. Ministério da Saúde. 10 passos para uma alimentação saudável para pessoas adultas. Brasília: Ministério da Saúde; 2007.

22. Brasil. Ministério da Saúde. Humaniza-SUS: Política Nacional de Humanização. Brasília: Ministério da Saúde; 2004.

23. Brasil. Ministério da Saúde. Matriz de ações de alimentação e nutrição na atenção básica de saúde. Brasília: Ministério da Saúde; 2009.

24. Ceccim RB, Armani TB, Oliveira DLLC, Bilibio, LF, Moraes M, Santos ND. Imaginários da formação em saúde no Brasil e os horizontes da regulação em saúde suplementar. Ciênc. Saúde Coletiva 2008; 13(5):14138123.

25. Buss PM, Ferreira JR. Atenção primária e promoção da saúde. In: Brasil. Ministério da Saúde. Projeto promoção da saúde. Brasília: Ministério da Saúde; 2001. p. 7-14. Nutritionists in primary health care: the user's viewpoint Demetra; 2014; 9(2); 483-501 501

26. Buss PM. Trabalho e subjetividade: cargas e sofrimento na prática da nutrição social. Rev. Nutr. 2000; 13(2):107-115. 27. Lopes EM, Anjos SJSB, Pinheiro AKB. Tendência das ações de educação em saúde realizadas por enfermeiros no Brasil. Rev. Enferm. 2009; 17(2):273-277 